\title{
TMS Chapter Holds Topical Conference on Micrometallurgy
}

The Northern California Chapter of The Metallurgical Society (TMS) sponsored a topical conference entitled "Micrometallurgy '88: Nontraditional Metallurgy in a Changing Environment" March 10-11, 1988 at Lake Tahoe, Nevada. The conference was designed to draw together individuals working in metallurgical areas involving the study of phenomena that $O c$ cur at a fine microstructural scale. The conference addressed a wide range of topics within the area of micrometallurgy, from the fundamental nature of nanocrystalline materials to the processing of fine metallic particles for use in powder metallurgy.

The topical conference, organized by a regional TMS chapter but with participation by scientists and engineers from across North America, Europe and the Far East, was clearly run as an experimental effort. Broad interest in the conference by contributing authors and attendees not presenting papers suggests that the experiment was quite a success. The Northern California Chapter of TMS was pleased with the response to their efforts and is considering organizing similar topical conferences on an alternate year basis. At the discretion of the authors, a collection of papers presented at the conference will be published in Materials Science and Engineering.
The conference was structured into five topical sessions: (1) Physical Micrometallurgy: Characterization of Ultrafine Structures, (2) Thermodynamics of Micrometallurgy: Prediction of StructureProcessing Relations, (3) Ultrafine Powder Metallurgy: Powder Processing and Production Techniques, (4) Multi-Microlayer Metallurgy: Structure and Properties of Thick and Thin Films, and (5) a general topic poster session. The program also included a keynote dinner lecture by A.R.C. Westwood, Martin-Marietta Corporation, on "Materials for Advanced Structures and Devices."

The first session, Characterization of Ultrafine Structures, was a materialsoriented session rather than an analytical techniques session, although all the papers utilized one or more microanalytical techniques such as high resolution TEM, analytical electron microscopy or microradiography. The variety of materials discussed was quite broad, including metallizations in microelectronic devices, metallurgical powders, intermetallic alloys, and composites.

The second session, Prediction of Structure-Processing Relations, comprised a collection of theoretical papers. Again, the topics were quite varied and included the effect of grain boundary segregation on mechanical behavior, microstructural evolution, and phase stability in alloy systems containing intermetallic compounds.

The third session, Powder Processing and Production Techniques, began with several invited papers on the new area of nanocrystalline materials. The papers emphasized transport phenomena in these materials, from the perspective of both fundamental measurements and also sintering rates in these materials. The remaining papers described recent work on the production of metallic powders for powder metallurgy applications and the fabrication of fine magnetic oxide powders for use in recording media.

The final session, Multi-Microlayer Metallurgy: Structure and Properties of Thick and Thin Films, discussed the fabrication and characterization of artificially structured multilayer materials and thick and thin film metallizations. Fabrication procedures including physical vapor deposition, sputtering and molecular beam epitaxy were considered. Characterization techniques including TEM, conventional $x$-ray diffraction, extended $x$-ray absorption fine structure (EXAFS), and recent techniques of characterizing the mechanical properties of thin films by various micromechanical testing procedures.

A.D. Romig, Jr.

\section{U.S. - Sweden Joint Symposium to Offer International Exchange on Materials Futures}

Recognized leaders in the materials field will participate in the U.S.-Sweden Joint Symposium on Materials Futures: Strategies and Opportunities, October 1819, 1988, Philadelphia, Pennsylvania. American and Swedish scientists and business leaders will focus on a unique balance of technical opportunities, management strategies, and industry success stories.

Keynote speakers include M.L. Good, president, Engineered Materials Research, Allied Signal, Inc. and R. Kiessling, professor and research scientist, Swedish Institute for Metals Research. Good will speak on "Chemical Research: The Heart of Materials Development." Kiessling's topic is "The Swedish Steel Industry: A Continuing Development from Suppliers of Raw Materials to Complete Success."
The Materials Research Society will publish the proceedings of this international exchange. Speakers for the session on success stories include P.R. Bridenbaugh (Alcoa), P. Weisz (University of Pennsylvania), and L. Ameen (Kanthal Development AB). The technical opportunities session will feature M.S. Steinberg (Lockheed), S. Ericsson (SaabScania), P. Chaudhari (IBM), R. Lagneborg (Swedish Institute for Metals Research), L. Ramqvist (LM Ericsson Telephone Co.), D. Apelian (Drexel University), and J.N. Zemel (University of Pennsylvania). Management strategy speakers include B. Kredell (ASEA Brown Boveri Ltd.) J.R. Johnson (3M Company), I. Fernlund (SKF Group Headquarters), and P. Lorange (Wharton School).

Post-symposium tours will offer continued exchange through several topical op- tions:

- Composite Materials-presentations by core faculty in composite materials research at Drexel University and by core faculty of the University of Delaware Center for Composite Materials;

- Biomaterials/Bioengineering-tours of several laboratories at the University of Pennsylvania (Biointerfaces, Biomaterials and Biomechanics, McKay Laboratory of Orthopaedics Surgery Research) and presentations by core faculty at the Drexel University Biomedical Institute;

- Materials Research-tour of the Laboratory for Research on the Structure of Matter at the University of Pennsylvania.

The symposium is limited to 126 participants. For information contact: R. Byron Pipes, Dean, College of Engineering, University of Delaware, Newark, DE 19716; telephone (302) 451-8302. 